\title{
A constituição do trabalho escravo como um acontecimento
}

The constitution of slave labor as an event

La constitución del trabajo esclavo como un evento

\author{
Geise do Socorro Lima Gomes \\ Universidade Federal do Pará, Belém, PA, Brasil. \\ Flávia Cristina Silveira Lemos \\ Universidade Federal do Pará, Belém, PA, Brasil.
}

\begin{abstract}
Resumo
O artigo visa debater a criação do objeto trabalho escravo em um campo de lutas de saber e poder em que o mesmo é resultante de práticas datadas e múltiplas, heterogêneas e raras. Também descreve um conjunto de lugares institucionais e posições de sujeito constituídas no bojo da elaboração do objeto, concomitantes aos conceitos e condições de possibilidade de aparecimento do acontecimento que ora é analisado. A política produzida como proteção frente ao jogo de tentativas de definição do objeto é correlata de uma maneira de pensar o mesmo e de descrevê-lo ainda que provisoriamente. Essa pesquisa foi realizada com uma análise histórica, documental e com contribuições de Foucault.

Palavras-chave: Trabalho escravo; Documentos; História.
\end{abstract}

\begin{abstract}
This article aims to discuss the creation of the object slave labor in a field of knowledge and power struggles in which it is dated and practices resulting from multiple, heterogeneous and rare. It also describes a set of institutional locations and subject positions constituted the core of the development of object concepts and concomitant conditions of possibility of occurrence of the event which is now analyzed. The policy produced as protection against the game attempts to define the object is related to a way of thinking the same and still describe the same provisionally, since the fights are still configuring and only battles were won. This research was conducted with a historical, documentary and with contributions from Foucault.
\end{abstract}

Keywords: Slave labor; Documents; history. 


\section{Resumen}

El artículo tiene como objetivo debatir sobre la creación de la mano de obra esclava objeto en un campo de conocimiento y las luchas de poder en el que está fechado y prácticas resultantes de múltiple, heterogéneo y poco frecuente. También se describe una serie de lugares institucionales y posiciones de sujeto constituía el núcleo del desarrollo de los conceptos de objeto y las condiciones concomitantes de la posibilidad de ocurrencia del hecho que ahora se analiza. La política producida como la protección contra el juego trata de definir el objeto se relaciona con una forma de pensar lo mismo y aún describir la misma forma provisional, ya que las peleas se siguen creando y sólo se ganaron batallas. Esta encuesta se llevó a cabo con una perspectiva histórica, documental y las contribuciones de Foucault.

Palabras clave: El trabajo esclavo; Documentos; Historia.

\section{Introdução}

Este trabalho é uma parte de pesquisa de mestrado desenvolvida no Programa de Pós-Graduação em Psicologia. O objetivo do estudo, financiado pela CAPES foi realizar uma analítica histórica acerca da formação do campo de luta gerado na constituição do objeto "trabalho escravo".

Esse campo de lutas culminou na produção de documentos nacionais e internacionais produzidos por diversos grupos e que foram selecionados para compor as análises sobre a constituição desse acontecimento. Esses documentos são forjados e acionados, por sua vez, por diversos grupos/segmentos para eleger os trabalhadores rurais como população alvo de investimentos políticos e econômicos.
E, para questionar os lugares assentados e, muitas vezes cristalizados por diferentes grupos e instituições, procuramos "desmontar" os documentos selecionados para análise, com o intuito de desnaturalizar os discursos que compõem os mesmos documentos e que por sua vez disparam práticas de poder e de saber sobre trabalhadores, subjetivando-os simultaneamente aos processos de objetivação do trabalho como escravo, como análogo ao escravo ou ainda como forçado, dependendo do grupo e instituição em jogo.

Assim, baseadas nas contribuições de Michel Foucault, apresentamos algumas descrições e análises da produção do objeto trabalho escravo por meio de práticas correlatas e heterogêneas e seus efeitos, no presente, a partir de uma breve história das mesmas. 


\section{Acerca das práticas de exploração dos} trabalhadores rurais

A literatura levantada (Rezende, 2004; Le Breton, 2002; Martins, 1995; Esterci, 1994) permite recortar um histórico sobre a produção da visibilidade dada às práticas de "exploração de trabalhadores rurais", no Brasil, associando sua divulgação às denúncias realizadas, principalmente pela Comissão Pastoral da Terra (CPT), por volta dos anos 70 e 80, no século XX. A CPT passou a nomear estas práticas de trabalho escravo.

Antes desse período e nomeação, essas práticas eram classificadas como "irregularidades trabalhistas" e o Estado brasileiro negava a existência das mesmas, conforme podemos investigar nos relatos dos movimentos denunciantes.

Em outros países, práticas semelhantes, que envolviam uma série de eventos classificados como desrespeito aos direitos trabalhistas, tais como a presença de violações de sua liberdade e, inclusive inúmeras práticas de torturas e violências diversas começaram a ser definidas como um mesmo objeto pela Organização Internacional do Trabalho (OIT), denominado de "trabalho forçado".

O objeto "trabalho forçado" se torna uma tipificação internacional, cunhada pela OIT, uma agência multilateral ligada à Organização das Nações Unidas (ONU) e que a partir da elaboração de duas Convenções: a de N. 29 e a de N. 105, que formulam proposições que visam eliminar tais práticas em todo o mundo, pelos países que aceitaram pactuar tais Convenções. Sendo assim, de acordo com a Convenção 29 da OIT: “[...] trabalho forçado ou obrigatório compreenderá todo trabalho ou serviço exigido de uma pessoa sob ameaça de sanção e para o qual não se tenha oferecido espontaneamente" (OIT, 2008).

O Brasil foi um dos países, integrante da OIT que assinou esta Convenção, e comprometia-se a erradicar essas práticas do país. E, devido ao não cumprimento desse acordo; segmentos da sociedade civil organizaram-se denunciando as situações desta condição de trabalho, no Brasil às várias instituições internacionais, como uma forma de fazer pressão e dar visibilidade para as práticas em questão.

As denúncias geralmente versam sobre: falta de cumprimento dos direitos trabalhistas, configurados nas extensas horas de trabalho, sem pagamento; falta de registro da carteira; condições de higiene e salubridade inadequadas; e violências cometidas pelos empregados dos contratantes/fazendeiros/empresários: práticas diversas que se configuram como 
torturas: chicoteamento, coronhadas, acorrentamento, partes do corpo mutiladas, assassinatos e humilhações verbais e ameaças. A presença de "capangas" armados é outra característica citada, como elemento que garantiria a coerção desses trabalhadores (Loreiro \& Pinto, 2005; Sakamoto, 2004; Le Breton, 2002; Rezende, 2000; Martins, 1997).

Por conta da variedade de situações e violências sofridas por esses trabalhadores, uma vez que estas práticas não se restringem ao meio rural, mas são realizadas também nas carvoarias; nas fábricas principalmente as têxteis; nos espaços domésticos; um número crescente de nomeações foi emergindo. Dependendo do setor da sociedade que se manifestava, cada prática ganhava visibilidade com uma denominação, que este setor julgava ser a "mais pertinente".

Uma série de processos de objetivação implicava em nomeações e demandas diversas, dependendo dos campos de saber e poder em que o acontecimento resultava de entrecruzamento de forças específicas. Os lugares institucionais, as posições subjetivas, os temas e conceitos, as modalidades enunciativas iam delimitando condições de possibilidade para o aparecimento dos objetos. Assim, de acordo com Esterci (1994) temos como exemplo: trabalho semiescravo; superexploração de mão de obra; escravidão branca; escravidão contemporânea; neoescravidão etc.

Essa variedade de nomenclaturas, por sua vez, é entendida por alguns pesquisadores como um "entrave" ou "empecilho" para a investigação dessas práticas e seu consequente julgamento (Jardim, 2007; Sento Sé, 2000). De acordo com suas opiniões, é preciso que haja um "consenso" sobre a denominação dessas práticas, para que medidas de punição e enfrentamento possam ser aplicadas (Martins, 2009; Moura, 2006; Rezende, 2004). No entanto, um dos maiores debate que se apresenta compondo os discursos sobre essas práticas diz respeito à relevância ou não dada ao acontecimento, caso um ou outro nome seja o "escolhido".

Notamos, então, a configuração de um campo de luta, que na disputa pela definição, parte em busca de uma "essencialização" dessas práticas e resulta em implicações de poder diferenciadas. Nesse campo são produzidos regimes de visibilidade e de dizibilidade a partir de posicionamentos quanto às práticas em questão, suscitando um campo discursivo heterogêneo entre os pesquisadores e movimentos sociais, além de práticas de poder correlatas, sobretudo, as que 
demandam uma lógica penal para os que lucram com estas práticas.

E, na tentativa de desnaturalizar os discursos que engendram as práticas de "exploração de trabalhadores rurais", buscou-se nessa pesquisa, dar visibilidade a esse emaranhado de enfrentamentos que vão se materializar na produção de documentos. E, em nenhum momento nos colocamos como defensores de qualquer forma de violência e de exploração de trabalhadores, essa pesquisa tentou questionar os outros lugares ocupados e, muitas vezes consolidados por determinados grupos, que dizem "defender" esses trabalhadores, nos perguntando de que forma esses grupos são convidados a legislar sobre a vida dessas pessoas? Para questionar esses "lugares", trabalhamos com a perspectiva foucaultiana, que nos ajudou no recorte dos documentos de acordo com as orientações a seguir.

\section{Ferramentas de análise}

Os documentos escolhidos para a realizarmos a pesquisa do campo heterogêneo de práticas de saber e de poder que objetivam o "trabalho escravo" foram: 08 dissertações publicadas no arquivo intitulado banco de dissertações e teses da CAPES, na internet, para dar visibilidade às discussões geradas no meio acadêmico; a Convenção 29 sobre o trabalho forçado ou obrigatório, a Convenção 105 relativa à abolição do trabalho forçado e o Relatório Global 2009 da OIT "O custo da coerção" como exemplo de documentos internacionais; o Relatório 2010 da OIT "Combatendo o trabalho escravo contemporâneo: o exemplo do Brasil" e os Planos Nacionais de Erradicação ao Trabalho Escravo: I (2003) e II (2008), como complemento à discussão no Brasil.

Esses documentos foram trabalhados a partir de uma análise baseada em apropriações que fizemos de conceitos de Michel Foucault, por meio da história arqueológica e genealógica, que consiste em realizar uma análise que não visa a "descoberta de essências", mas “[...] realizar uma análise histórica das condições políticas de possibilidades dos discursos" (Machado, 2006, p. 167).

Seguir o filão complexo da proveniência é, [...] manter o que se passou na dispersão que lhe é própria: é demarcar os acidentes, os ínfimos desvios - ou ao contrário as inversões completas - os erros, as falhas na apreciação, os maus cálculos que deram nascimento ao que existe e tem valor para nós; é descobrir que na raiz daquilo que nós conhecemos e daquilo que nós somos - não existe a verdade e o ser, mas a exterioridade do acidente. (Foucault, 2008a, p. 21). 
O trabalho com documentos exige paciência, de acordo com Foucault (1979). Ele nos ensinou a pensar a produção dos documentos como arquivos, constituídos por práticas que são acontecimentos raros e singulares, datados e forjados por lutas.

Os documentos são montados, organizados e recortados, conservados e guardados de certo modo e em certo lugar e tempo, portanto, têm história e são resultantes de forças distintas e múltiplas, que se encontraram ao acaso e seu ponto de encontro é a emergência e sua aparição não tem intencionalidade. Assim, a genealogia permite a crítica da origem e da finalidade e a arqueologia possibilita a visão de descontinuidade que se atualiza por proveniências e dispersões.

É neste aspecto, que Le Goff (2003) destaca que: nenhum documento é inocente, devendo ser des-estruturado, desmontado e interrogado como um artifício que foi elaborado e organizado de certa maneira, em uma dada época e lugar específicos tal como um diagrama de forças dispersas e heterogêneas que se articularam. Logo, os documentos aqui apresentados foram analisados com esse intuito, de dar visibilidade à construção das práticas discursivas e das não discursivas que compõem os documentos, e de como estas se configuraram como dispositivos que objetivam as práticas e subjetivam os corpos, por sua vez, dos trabalhadores.

Para a identificação dessas práticas foram organizadas "séries" que funcionaram como operadores metodológicos ajudando a recortar os documentos, em determinados campos de luta que compõem os discursosacontecimentos. As séries recortadas para as análises ajudaram a ordenar e organizar os discursos destacados por temas, conceitos, lugares institucionais, posições de sujeito e pelas condições de possibilidade de aparecimento dos objetos.

Tanto nas dissertações estudadas quanto nos documentos da OIT, existe uma preocupação em definir as práticas de exploração dos trabalhadores. Definir essas práticas requer a formulação de justificativas que vão sendo elaboradas com o objetivo de chegar a um "consenso" pela produção de jogos de saber-poder, constituído por forças heterogêneas. Estes regimes de verdade operam também pela tipificação penal para facilitar a realização de um julgamento; que possibilite a criação de banco de dados com o cadastro dos trabalhadores que foram resgatados e que foram encaminhados para programas sociais; que favoreça o registro de documentos dos trabalhadores, como a carteira de identidade e de trabalho; que viabilize o pagamento dos direitos 
trabalhistas e de indenizações pelos danos sofridos etc.

Contudo, como eleger os elementos que irão servir de composição dos tais “dados"? Que critérios serão elaborados para avaliar se um caso se trata ou não de "trabalho escravo"? Essas questões são apresentadas posições que implicam em decisões a respeito das chamadas políticas públicas de enfrentamento à situação exemplificada, por diferentes agentes e órgãos governamentais e não governamentais.

A Organização Internacional do Trabalho recebe um destaque nos estudos sobre "trabalho escravo contemporâneo" por legislar a respeito das relações de trabalho no âmbito internacional. Por sua vez, acaba recebendo por diversos países, pedidos de auxílio na identificação das práticas, já que este órgão conseguiu agenciar grande reconhecimento e construiu ao longo de décadas uma expertise de pesquisa, de articulação política e de intervenções em muitos países nas situações de violações de direitos trabalhistas, em especial, nas que denominou de "trabalho forçado".

Diante das encomendas da OIT, os países são convocados a apresentarem os seus levantamentos sobre as situações denunciadas, por meio de relatórios de prestação de contas a respeito desta condição pelo fato dos mesmos terem assinados termos de compromisso com a OIT e por terem ratificado as Convenções referentes a cada violação de direito trabalhista a que estas Convenções se referem.

A OIT assinala que muitos países, inclusive, o Brasil mascaram estes dados e até mesmo não têm arquivos com registros confiáveis a respeito, de acordo com o relatório 2009 dessa organização. A partir da entrega destes dados, a OIT orienta os países a criarem metodologias para pesquisas sobre o tema, que possam demonstrar o perfil dessas pessoas submetidas ao que delimita como trabalho forçado e que definam características específicas da mesma em seus territórios, bem como descreva quais são os locais de maior incidência destas práticas e que circunscreva as violações trabalhistas e outras (como as de liberdade) que estão sendo realizadas etc. Desse modo, podemos analisar como um campo administrativo penal vai se esboçando na política definida como de enfrentamento ao trabalho escravo e de que maneira a diplomacia interfere na situação de violação dos direitos trabalhistas.

Para Foucault (2008c), essa preocupação está baseada em uma biopolítica, que encontra um dispositivo de governo securitário, aliada aos saberes da 
informática, da estatística, da geografia, da demografia, da administração social e do direito penal. A partir dessa preocupação da OIT com a criação de protocolos de denúncia e com a organização destes em bancos de dados, podemos afirmar que os indicadores de violação de direitos trabalhistas são uma série discursiva recorrente nos documentos analisados nesta pesquisa.

Outra série recorrente é o clamor pela criminalização da situação em pauta, ou seja, da tipificação penal por meio do consenso de um nome que abarque a condição de escravidão, na atualidade, para que seja estipulado, concomitantemente o quadro jurídico das respectivas leis e penalidades frente à emergência dos enunciados de ilegalidade. Embora conste, desde 1940, no Código Penal Brasileiro, que as práticas associadas à escravidão contemporânea figurem como crimes; ainda se evidencia um discurso de intenso clamor pela "criminalização" dessas práticas e a punição dos considerados "culpados".

O “clamor” pela criminalização traz novas práticas jurídicas para a situação em termos de maior delimitação das penas e, sobretudo, de endurecimento das mesmas. Podemos então, exemplificar com um extrato de dissertação pesquisada sobre o assunto:
Assim, temos questões como o descumprimento da legislação brasileira. Não podemos nos esquecer da brandura e da permissividade da legislação trabalhista e da Constituição Federal, quando consideramos os julgamentos e punições dos crimes de trabalho escravo, os quais apresentam pena mínima de dois anos e máxima de oito anos, prevista no artigo 149 do Código Penal, podendo ser aplicados ainda certos dispositivos para atenuar a pena, com sua conversão em prestação de serviços à comunidade ou distribuição de cestas básicas, isto quando o crime não prescreve. Em 2005, dos 17.983 trabalhadores libertados em 1.463 fazendas fiscalizadas, houve poucos casos de condenação, sendo que em nenhum desses os réus cumpriram pena de reclusão, dando à questão uma conotação menos importante, o que de certa forma incentiva a continuidade dessa prática. (Pereira, 2007, p.115-116).

De acordo com Passetti (2003, p. 132), “[...] delimita-se o crime como algo que atenta contra a sociedade e não contra indivíduos, sua vida ou seus bens". Esse discurso presente na literatura brasileira é muito próximo do discurso proferido pela OIT (2009), quando incentiva os paísesmembros a reverem suas legislações para procurar adequá-las à demanda da criminalização e da punição referentes às práticas de exploração dos trabalhadores. Contudo, o objetivo maior que 
visualizamos na esfera internacional é transformar a definiç̧ão geral elaborada por esta agência, como uma tipificação penal internacional. Desse modo, um tribunal internacional, poderá algum dia, futuramente, atuar no julgamento desses casos em qualquer lugar do mundo, uma vez que generalizadas as situações, a intervenção pela agência seria possível.

Essa intervenção já se presentifica não só com o consentimento do pacto estabelecido entre os países, mas bem como, por meio das propostas e cartilhas, orientações diversas elaboradas pela agência e direcionadas a determinados profissionais para que atualizem seus trabalhos à demanda do "clamor" securitário e penal do neoliberalismo, criando assim espaços e posições de sujeitos da verdade específicos desta determinada sociedade.

Os juízes tem tido por vezes que enfrentar novos conceitos de servidão por dívidas, de práticas de escravatura e de exploração laboral. Muitas vezes, a dificuldade na interpretação de nova legislação é passada para o poder judicial, e onde possa existir jurisprudência, e, quer em países de direito comum ou de direito civil, devem aprender uns com os outros. Para orientar a prática judicial, e para assegurar que os instrumentos da OIT sobre trabalho forçado são considerados em julgamentos futuros, foi publicado em 2009, uma coletânea de jurisprudência sobre o trabalho forçado destinado a juízes e promotores públicos. (OIT, 2009, p. 02).

As orientações elaboradas para os juízes, também ganham suas versões destinadas a outros segmentos da sociedade, como os sindicatos e inspetores do trabalho, configurando dispositivos biopolíticos que atuarão sobre a vida de determinadas populações, como a dos trabalhadores, já que estas foram eleitas como público alvo e irão passar por um controle exercido por medidas e mecanismos que poderão fazer viver e deixar morrer, na esfera da segurança e da saúde. É neste aspecto que a biopolítica é exercida como prática de poder e saber, em sua positividade também e em termos de vinculação entre economia política com a soberania jurídica.

Há uma ampliação da gestão do poder, que de acordo com Foucault (2005) para que se engendre nas diferentes esferas da vida, tanto no âmbito individual como no coletivo e, no caso da biopolítica, a regulação é da totalidade de um segmento ou pelo menos da tentativa de. E, acrescenta o autor, essa economia do poder não pode funcionar sem uma produção de verdade. E uma questão é a luta pela delimitação e produção da verdade, que poderá ser a dos documentos analisados ou de outros registros e instâncias correlatas. 
Assim, os discursos do objeto direitos humanos e das práticas de "trabalho escravo" como um crime grave e que deve ser punido é um destes regimes de verdade e da recomendação de poder coextensiva ao mesmo. Neste aspecto, podemos observar que outra série recorrente nos documentos é dos direitos humanos.

As intervenções realizadas pelos diferentes grupos que atuam frente ao objeto trabalho escravo geralmente baseiam-se no discurso da garantia e promoção dos direitos humanos. E, no caso para garantir estes direitos, é proposta uma posição de sujeito denominada de "trabalhador" e "pessoa" que se reconheça como "escravo".

Ou seja, a partir do conjunto de características discursivas levantadas como constitutivas do objeto trabalho escravo contemporâneo, cada trabalhador que desejar ser alvo da proteção e garantia respectiva ao campo de formação discursiva produzido, deverá identificar-se e aceitar ser classificado por este crivo. A situação de escravidão seria um agravante frente a outras violações de direitos trabalhistas e criaria um campo de políticas compensatórias diferenciadas para os trabalhadores identificados nesta posição subjetiva.
A questão é que outras formas de exploração no trabalho se tornam menos graves diante da escravidão e terão menos atenção de uma política, pois, no neoliberalismo, a lógica penal e a equitativa passa a vigorar como central frente à ampla defesa de direitos fundamentais e; sobretudo, de financiamento de políticas estatais que garantam todos estes direitos. Assim, o que produz a escravidão não é alvo da política atual, pois são trabalhadores explorados e, em progressiva situação de exclusão pela não garantia de um conjunto de seus direitos fundamentais que irá conduzi-los para a escravidão como um último recurso de "sobrevivência".

Percebemos nos discursos dos documentos nacionais e internacionais que há um movimento de desprestígio dos direitos civis, políticos e sociais e que somente a urgência dos limites mais extremos tem sido alvo de alguma forma de compensação pelo Estado brasileiro como decisão política para lidar com as violações.

Para Coimbra (2000) o foco para os direitos humanos recebe uma construção cotidiana, portanto, histórica. Se alguns acontecimentos vão emergir como sendo casos de "violação dos direitos humanos" ou não, vai depender dos efeitos das relações de forças em um contexto 
temporal e social. E para poder garantir o lugar de "humano a ser protegido" pela condição de sobrevivente, é montada uma rede de proteção com práticas de peritos e de especialistas que formam o que designamos de "complexo tutelar".

Emprestamos de Donzelot (1986) o conceito de Complexo tutelar para falar da "tutela" que de certo modo acaba sendo exercida sobre os trabalhadores, que infantilizados pela maneira como seus direitos são apresentados como favor e benesse de cunho moral. Muitos assessores com suas recomendações e reprodução das chamadas práticas exitosas visam tutelar os corpos dos trabalhadores resgatados em nome da defesa e proteção, todavia, sem ouvir os que sofrem a violação de direitos e sem valorizar suas falas e interesses.

\section{A luta de saber e poder pelas nomeações}

\section{dos acontecimentos}

A primeira, "trabalho forçado", é uma descrição mais difundida pelo aporte de divulgação e força de articulação política da OIT. O seu uso permite a intervenção dessa agência no Estado brasileiro, o que aponta para os processos de internacionalização do direito e da emergência de encomendas de julgamentos a serem realizados por um tribunal internacional. Embora o Brasil tenha assinado as Convenções da OIT, há grupos de resistência no país que propõem outras designações, por acharem que a designada pela OIT não corresponde às situações que ocorrem na realidade brasileira.

Assim, por exemplo, no nosso Código Penal, a designação constatada é de "Condições análogas a de escravo", forma encontrada pelo setor jurídico para enfatizar as situações encontradas no Brasil, que para alguns pesquisadores (Jardim, 2007; Jesus, 2005) preserva determinadas práticas efetuadas no Brasil Colônia, contudo, não sendo consideradas iguais. Para efeitos de julgamento e punição, deverão receber outra nomeação, já que o termo "trabalho escravo" corresponde a uma prática extinta no Brasil, desde a Lei Áurea, segundo os juristas brasileiros.

Para os movimentos sociais, a nomeação que se usa habitualmente é "trabalho escravo", vindo tocar justamente nas situações mais explícitas da reprodução de práticas coloniais de exploração do trabalho, atualizadas no presente.

E, por último, "condições degradantes de trabalho". Essa nomeação está inserida no Código Penal Brasileiro, complementando as características que evidenciam as práticas "análogas a de escravo". Contudo, essa definição também é fruto de tensões, mas há grupos que 
defendem o uso dessa expressão, relacionado-a ao "trabalho escravo" somente se vier acompanhada da situação da falta de liberdade. É uma discussão gerada entre os procuradores do trabalho e os dos direitos civis que por um lado, também procuram demarcar sua posição nesse jogo de saber poder, gerado na discussão do tema "trabalho escravo".

\section{Algumas considerações finais}

O objeto trabalho escravo difere do trabalho forçado e, por sua vez, das condições análogas à escravidão e ainda do objeto exploração do trabalho, entre outras nomeações utilizadas pelos grupos em disputa. De qualquer forma, os acontecimentos se materializam em sua raridade e singularidade e, por isto, os termos que são criados para governá-los são práticas datadas e maneiras de enquadrar que não dão conta da multiplicidade em jogo, apesar de destacarem a existência de um campo de preocupações políticas com o que nos acontece no presente e o que produzimos como efeito de um determinado modo de recortar e nomear os acontecimentos.

\section{Referências}

Brasil. (2003). Plano Nacional para a Erradicação do Trabalho Escravo. Brasília: OIT.

. (2008). Plano Nacional para a Erradicação do Trabalho Escravo, II. Brasília: SEDH.

Coimbra, C. (2000). Psicologia, Direitos Humanos e Neoliberalismo. Revista Psicologia Política, v.1, n.1, julho.

Esterci, N. (1994). Escravos da desigualdade: estudo sobre o uso repressivo da força de trabalho hoje. Rio de Janeiro: CEDI.

Foucault, M. (2005). Em defesa da sociedade. 25. ed. São Paulo: Martins Fontes.

. (2008a).Nietzsche, a genealogia e

a história. In: Microfísica do poder. Org. e Trad.: Roberto Machado. 25. ed. Rio de Janeiro: Graal.

. (2008b). A Arqueologia do Saber.

7. ed. Rio de Janeiro: Forense Universitária.

- (2008c). Segurança, Território e População. São Paulo: Martins Fontes.

Jardim, P. G. (2007). Neoescravidão: as relações de trabalho escravo contemporâneo no Brasil.

Dissertação (Mestrado) - Programa 
de Pós-Graduação em Direito. UFPR. Curitiba.

Jesus. J. G. de. (2005). Trabalho escravo no Brasil contemporâneo: representações sociais dos libertadores. Dissertação (Mestrado em Psicologia Social e do Trabalho) - UnB, Brasília.

Le Breton, B. (2002). Vidas roubadas: a escravidão moderna na Amazônia brasileira. 2. ed. São Paulo: Loyola.

Loreiro, V. R.; Pinto, J. N. A. (2005). A questão fundiária na Amazônia: algumas fontes para a compreensão do problema atual. , São Paulo, Estudos avançados, 19 (54).

Machado, R. (2006). Foucault, a ciência e o saber. 3. ed. Rio de Janeiro: Jorge Zahar.

Martins, J. de S. (1995). A reprodução do capital na frente pioneira e $\mathrm{o}$ renascimento da escravidão. Tempo Social - Revista de Sociologia. USP, SP, 6 (1-2), p. 1-25. . (1997). Exclusão Social e a Nova Desigualdade. São Paulo: Paulus. Organização Internacional do Trabalho. (2008). Convenção 29 sobre o trabalho forçado ou obrigatório. Disponível em: http://www.oitbrasil.org.br/inst/fun d/docs/index.php. Acesso em: 07 out. 2008 .
- (2009). O custo da coerção. Relatório Global no seguimento da Declaração da OIT sobre os Direitos e Princípios Fundamentais do Trabalho. Disponível em: http://www.oitbrasil.org.br/inst/fun d/docs/index.php. Acesso em: 06 mar. 2009.

Passetti, E. (2003). Anarquismos $e$ sociedade de controle. São Paulo: Cortez.

Pereira, A. (2007) Os desafios para o trabalho nas carvoarias de Ribas do Rio Pardo/MS. 2007. Dissertação (Mestrado) - Programa de Pós-Graduação em Geografia, Universidade Estadual Paulista "Júlio Mesquita", Presidente Prudente..

Rezende, R. (2000). Por que o trabalho escravo. São Paulo, Estudos Avançados, vol. 14, n. 38, jan. Pisando Fora da Própria Sombra: a escravidão por dívida no Brasil contemporâneo. Rio de Janeiro: Civilização Brasileira, 2004.

Russo, A. M. V. Os direitos humanos e a escravidão por divida do trabalhador brasileiro. 2005. Dissertação (Mestrado) - Programa de Pós-Graduação em Direito, Universidade do Vale do Rio dos Sinos, São Leopoldo, 2005. 
Sakamoto, L. (2006). Nova escravidão traz mais vantagens econômicas para os patrões que a da época colonial. Disponível <http://www.reporterbrasil.org.br > Acesso em: 05 maio.

Sento-Sé, J. L. de A. (2000). Trabalho escravo no Brasil na atualidade. São Paulo: LTR.

Geise do Socorro Lima Gomes: Psicóloga no NASF, formada na UFPA. Mestre em Psicologia pela UFPA. Doutoranda em Educação na UFPA. Endereço: Avenida Augusto Côrrea, n. 01. Instituto de Filosofia e Ciências
Humanas/UFPA. Guamá, Belém do Pará/PA.

E-mail: geise@ufpa.br

\section{Flávia Cristina Silveira Lemos:} Psicóloga (UNESP), Mestre em Psicologia Social (UNESP), Doutora em História (UNESP). Professora adjunta III de Psicologia Social (UFPA).

Endereço: Avenida Augusto Côrrea, n. 01. Instituto de Filosofia e Ciências Humanas/UFPA. Guamá, Belém do Pará/PA.

E-mail: flaviacslemos@gmail.com 